\title{
GOCE data for local geoid enhancement
}

\author{
Herceg, Matija; Knudsen, Per; Tscherning, Carl Christian
}

Publication date:

2012

Document Version

Peer reviewed version

Link back to DTU Orbit

Citation (APA):

Herceg, M., Knudsen, P., \& Tscherning, C. C. (2012). GOCE data for local geoid enhancement. Poster session presented at GOCE Solid Earth Workshop , Enschede, Netherlands.

\section{General rights}

Copyright and moral rights for the publications made accessible in the public portal are retained by the authors and/or other copyright owners and it is a condition of accessing publications that users recognise and abide by the legal requirements associated with these rights.

- Users may download and print one copy of any publication from the public portal for the purpose of private study or research.

- You may not further distribute the material or use it for any profit-making activity or commercial gain

- You may freely distribute the URL identifying the publication in the public portal

If you believe that this document breaches copyright please contact us providing details, and we will remove access to the work immediately and investigate your claim 


\title{
GOCE data for local geoid enhancement
}

\author{
Matija Herceg ${ }^{1}$, Per Knudsen², Carl Christian Tscherning ${ }^{1}$
}

${ }^{1}$ Universtity of Copenhagen, Denmark, ${ }^{2}$ DTU Space, National Space Institute, Denmark

\section{Abstract}

The main objective of this study is to study how gradients can be used to extract more short wavelength information of the gravity field and to use this enhancement to improve modelling of ocean circulation, i.e. MDT in regional area. This is done by development of a method for regional gravity field recovery by using GOCE gradients in addition to the global models. The Least Squares Collocation method requires the solution of as many linear equations as the number of data, so GOCE gradient data needs to be thinned prior to applying the method. To overcome this thinning, a Reduced Point Mass (RPM) method is developed as a part of this study. The RPM is based on the reduced point mass response.

The results presented in this study are based on all available GOCE gradient data in the GOCINA region, i.e. 18 months of observations.

\section{Methods}

Point-mass functions or multipole base-functions are harmonic functions, which may be used to represent the (anomalous) gravity potential $T$ either globally or locally. The functions may be expressed by closed expressions or as sums of Legendre series. In both cases at least the two first terms must be removed since they are not present in $T$. For local applications the effect of a global gravity model is generally removed. Then, more terms need to be removed or substituted by terms similar to the error-degree variances. The Earth anomalous gravity field at one point is modeled by a set of base functions, each obtained as the anomalous gravity potential from each point.

$$
\begin{aligned}
& V_{\eta \eta}=\frac{1}{r^{2} \cos ^{2} \varphi} \frac{\partial^{2} V}{\partial \lambda^{2}}-\frac{\tan \varphi}{r^{2}} \frac{\partial V}{\partial \varphi}+\frac{1}{r} \frac{\partial V}{\partial r} \\
& V_{\xi \xi}=\frac{1}{r^{2}} \frac{\partial^{2} V}{\partial \varphi^{2}}+\frac{1}{r} \frac{\partial V}{\partial r} \\
& V_{\zeta \zeta}=\frac{\partial^{2} V}{\partial r^{2}}
\end{aligned}
$$
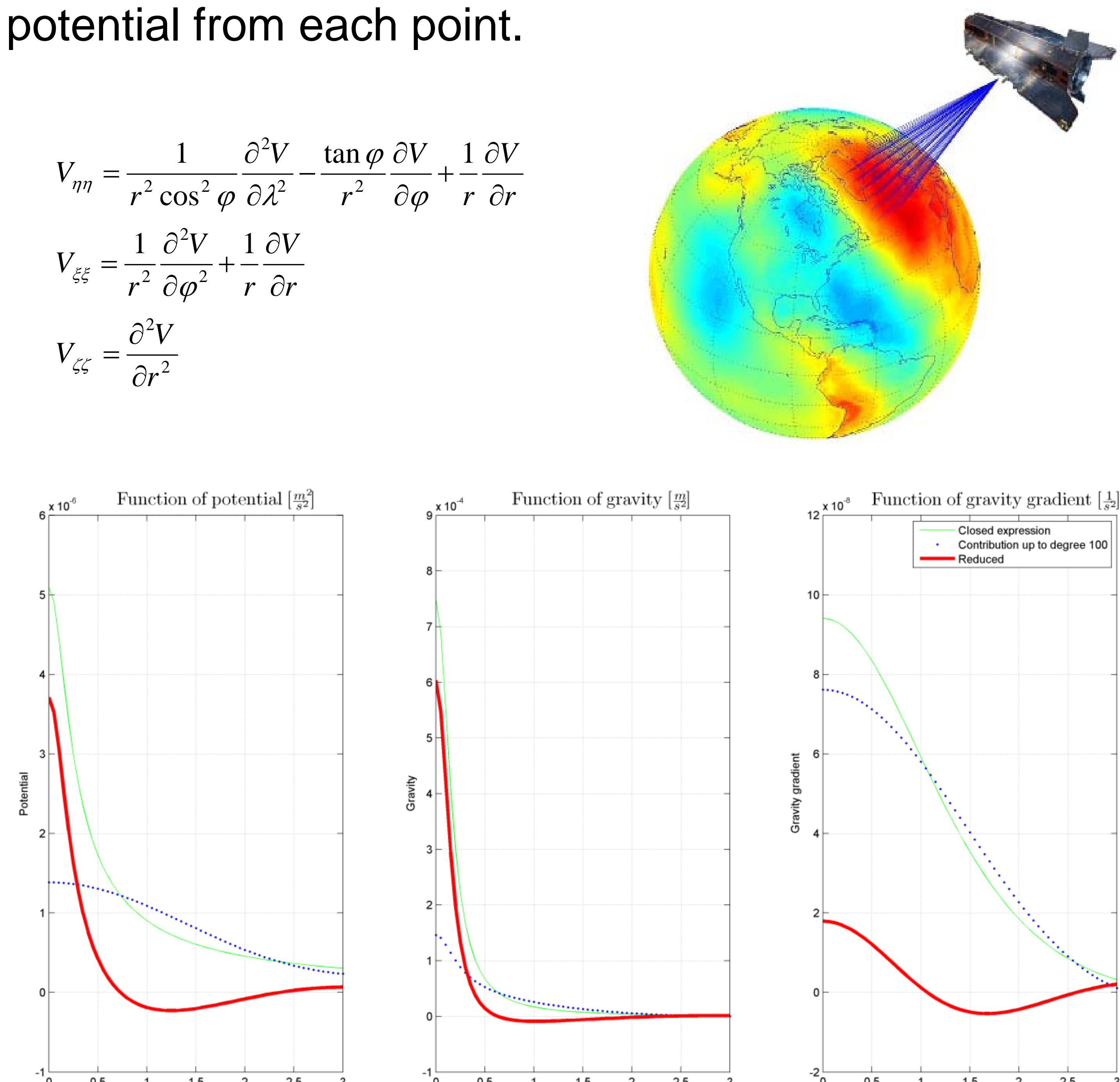

Closed expressions for gravity masses gradients when using point
Expressions for gravity gradients when using reduced point masses
$V_{\eta \eta}=3 \frac{r_{q}^{2}}{l^{5}} \cos ^{2} \varphi_{q} \sin ^{2}(\Delta \lambda)-\frac{1}{l^{3}}$

$V_{n \eta}=\frac{1}{r_{p}^{2} \cos ^{2} \varphi}\left[\frac{\partial V}{\partial t} \frac{\partial^{2} t}{\partial \lambda_{p}^{2}} \frac{\partial^{2} V}{\partial t^{2}}\left(\frac{\partial t}{\partial \lambda_{p}}\right)^{2}\right]-\frac{\tan \varphi_{p}}{r_{p}^{2}} \frac{\partial t}{\partial \varphi_{p}} \frac{\partial V}{\partial t}+\frac{1}{r_{p}} \frac{\partial V}{\partial r_{p}}$

$V_{\xi_{\xi}}=3 \frac{r_{q}^{2}}{l^{5}}\left(\cos \varphi_{q} \sin \varphi_{p}-\sin \varphi_{p} \cos \varphi_{q} \cos (\Delta \lambda)\right)^{2}-\frac{1}{l^{2}}$

$V_{\xi \xi}=\frac{1}{r_{p}^{2}}\left[\frac{\partial V}{\partial t} \frac{\partial^{2} t}{\partial \varphi_{p}^{2}}+\frac{\partial^{2} V}{\partial t^{2}}\left(\frac{\partial t}{\partial \varphi_{p}}\right)^{2}\right]+\frac{1}{r_{p}} \frac{\partial V}{\partial r_{p}}$

\section{Results}

Figures are showing geoid height anomaly predicted by the LSC and the RPM methods, when the EGM2008 up to harmonic degree and order 100 is subtracted.

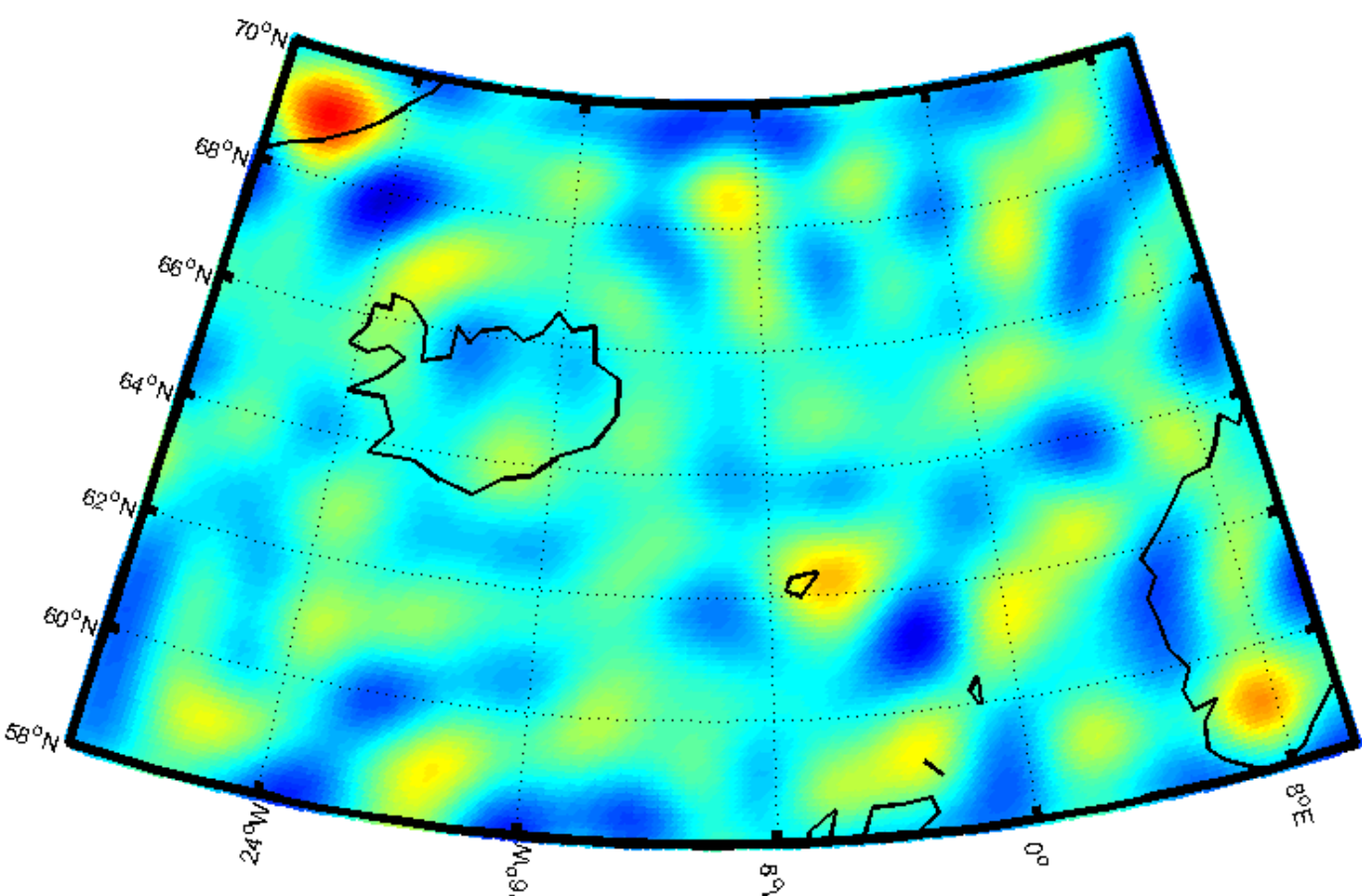

Geoid [m] predicted using the LSC method

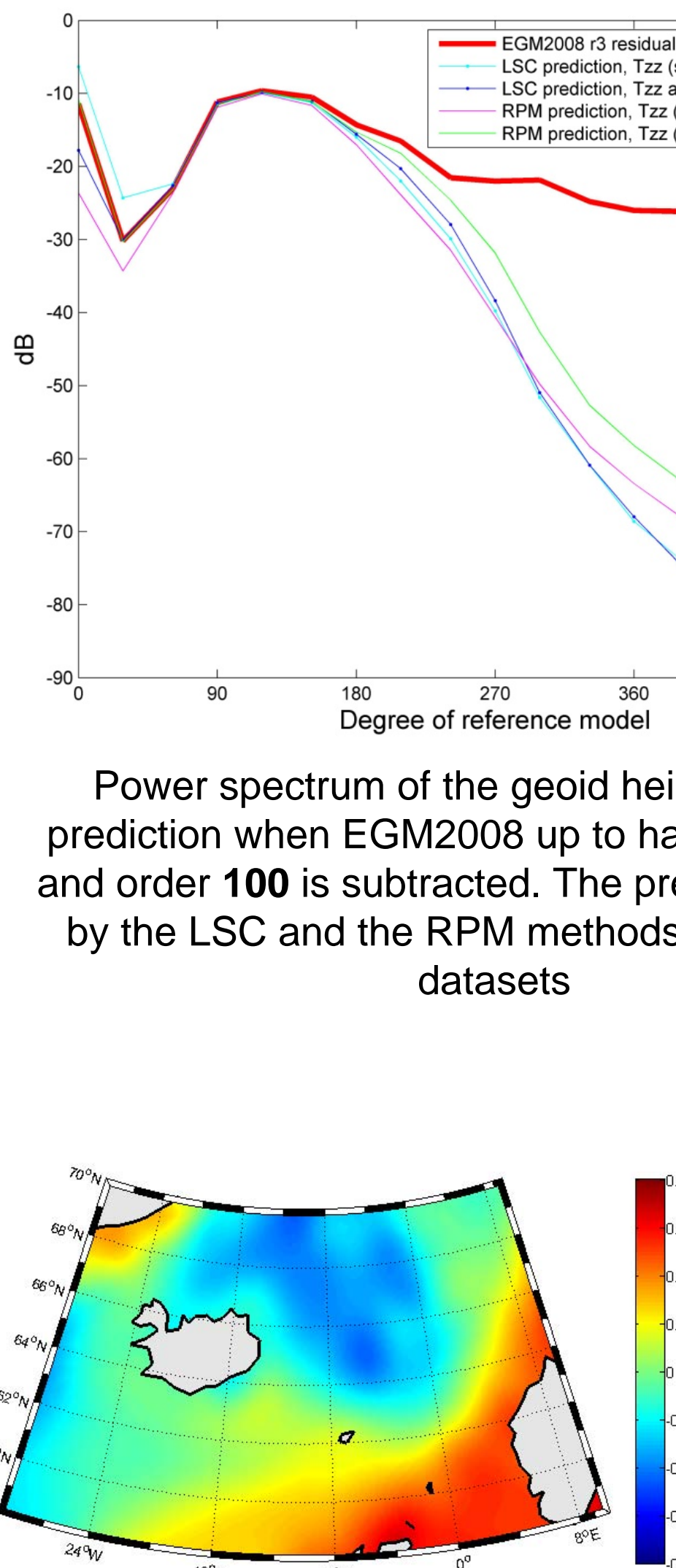

DTU10 MDT

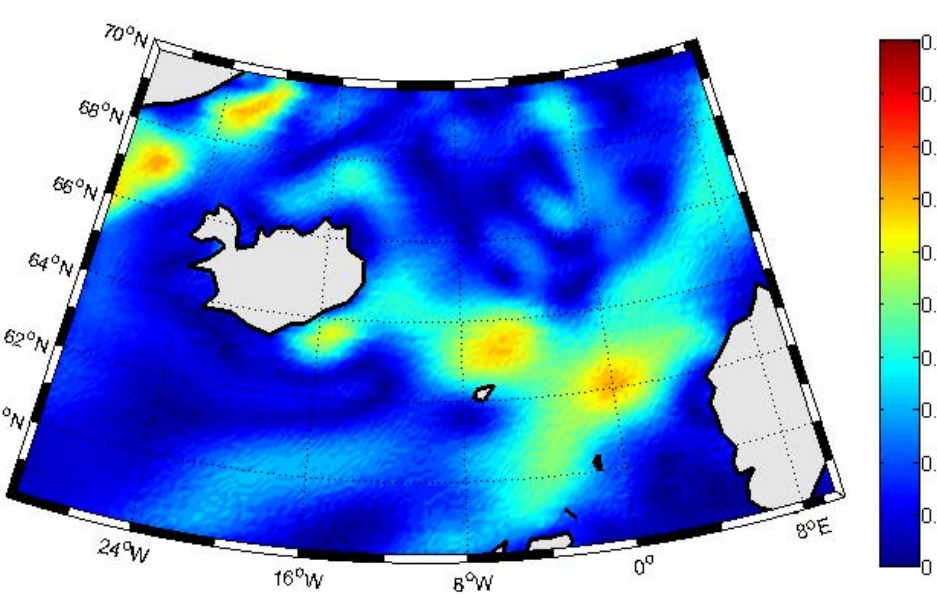

DTU10 current speed

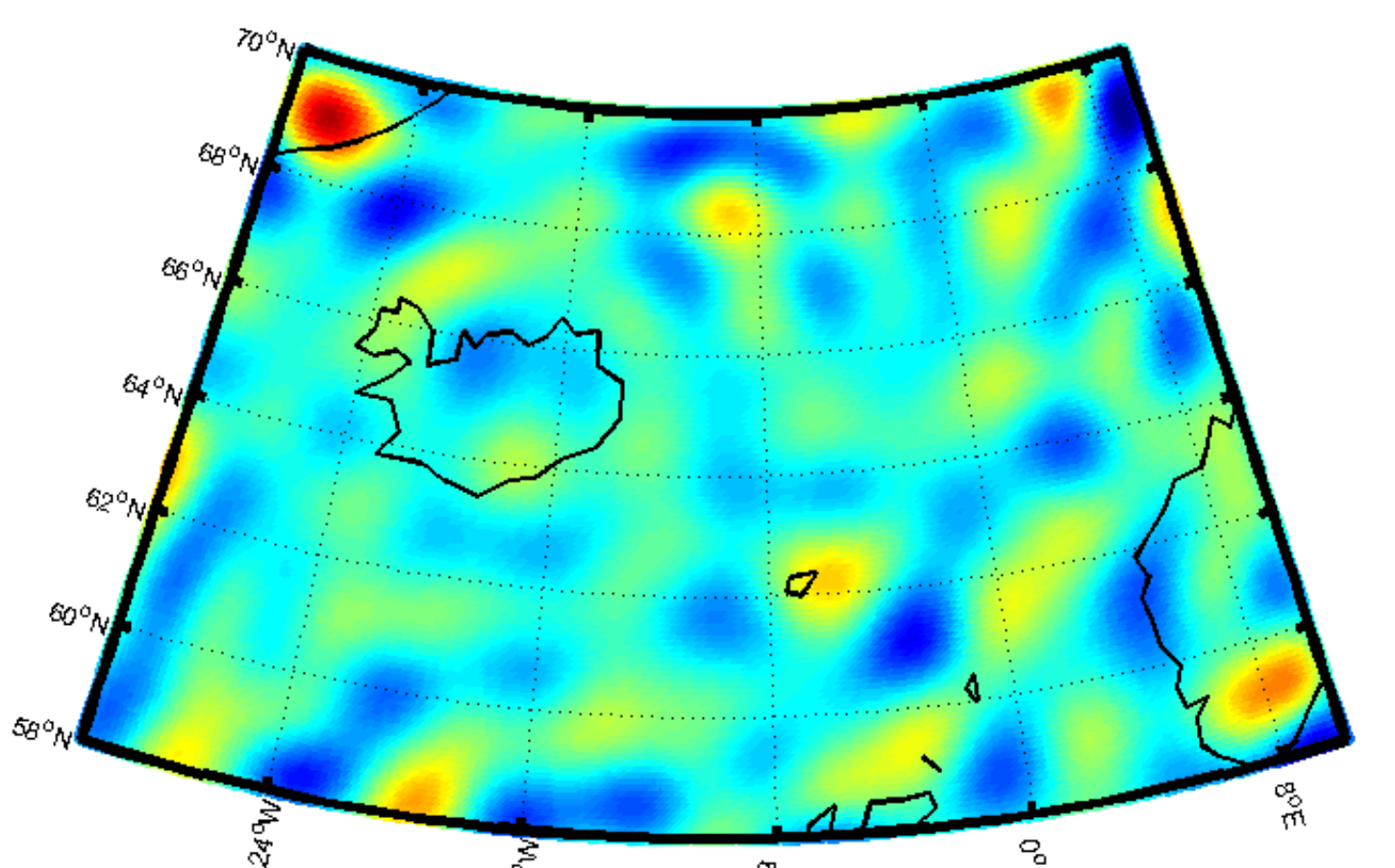

Geoid [m] predicted using the RPM method

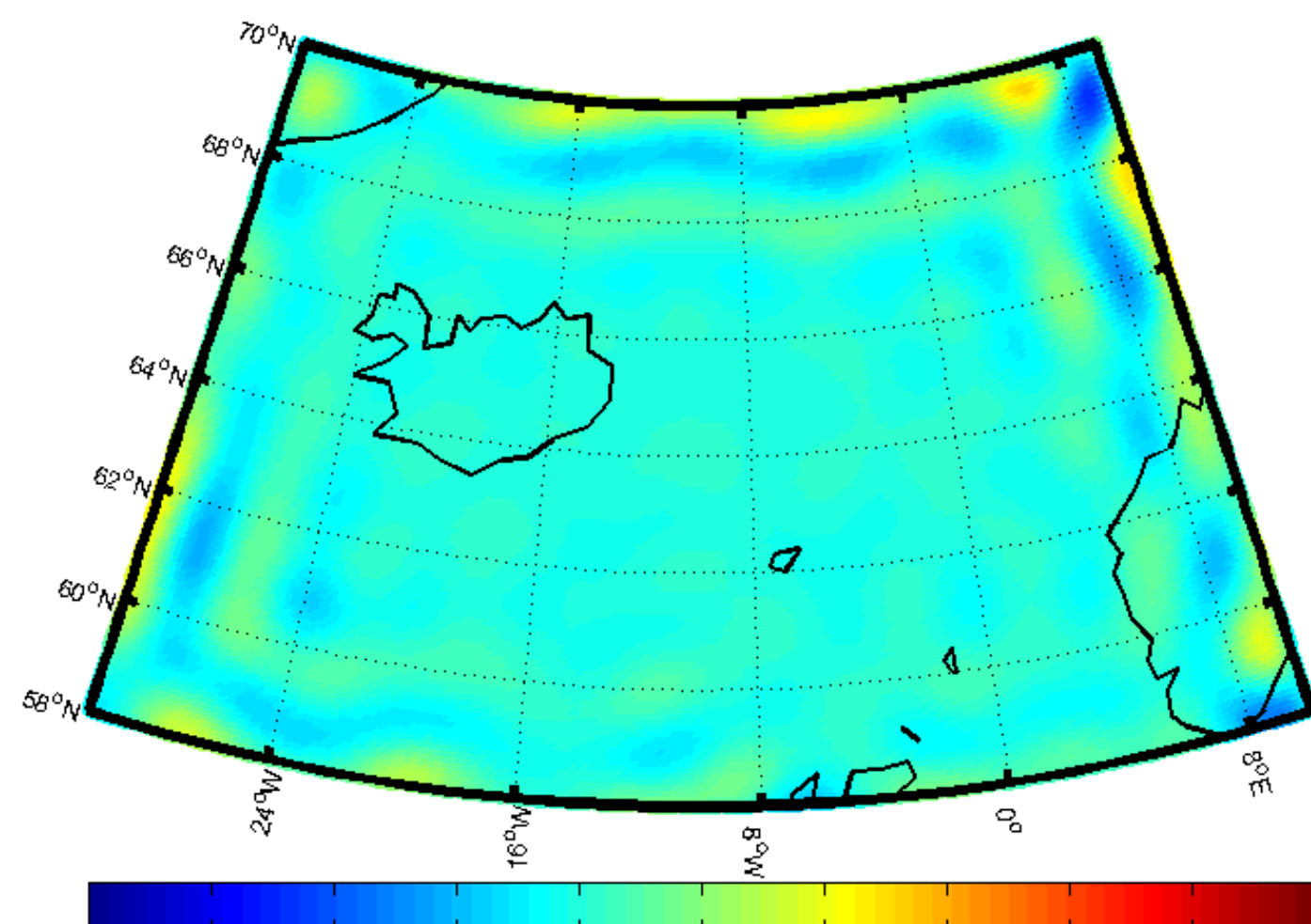

Difference between prediciton
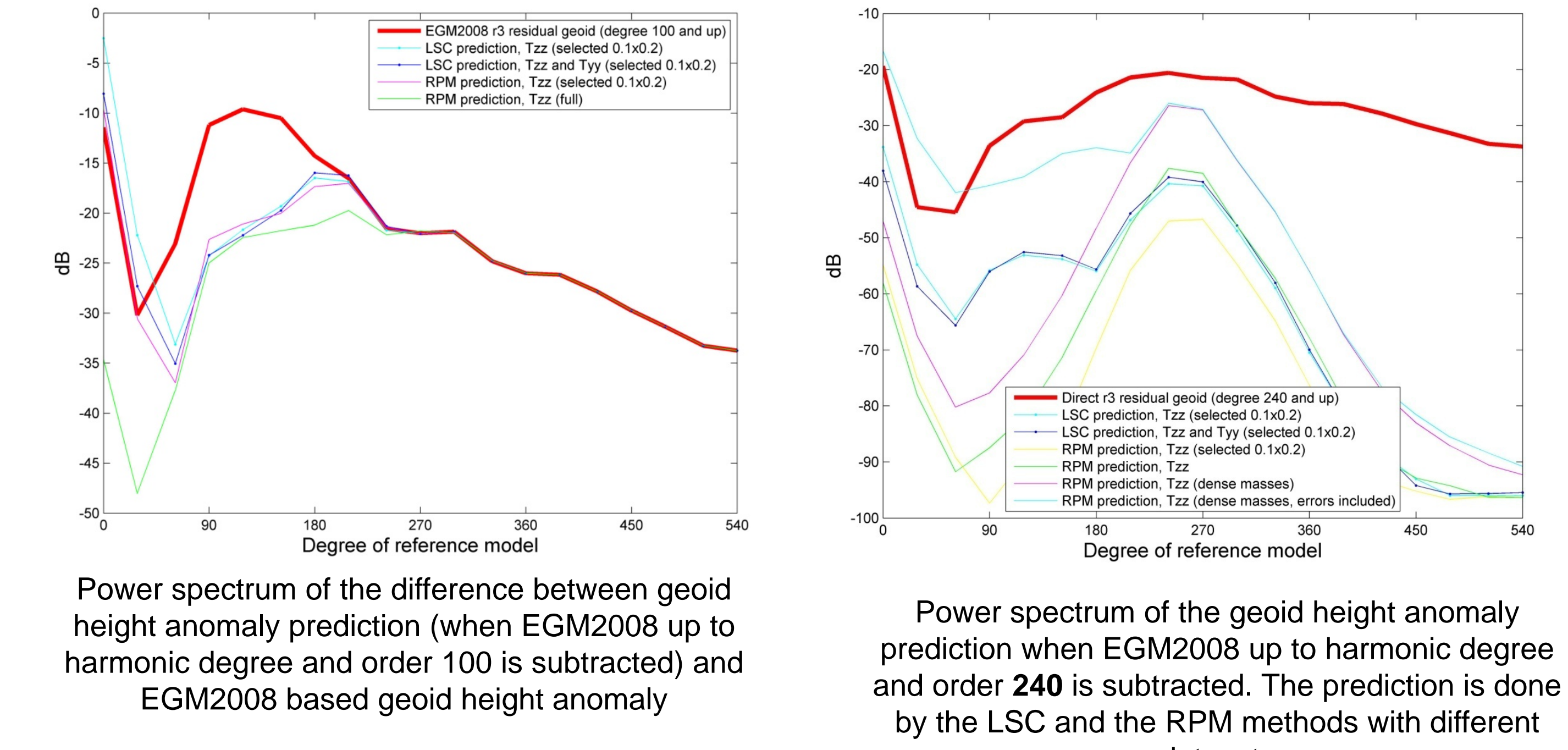

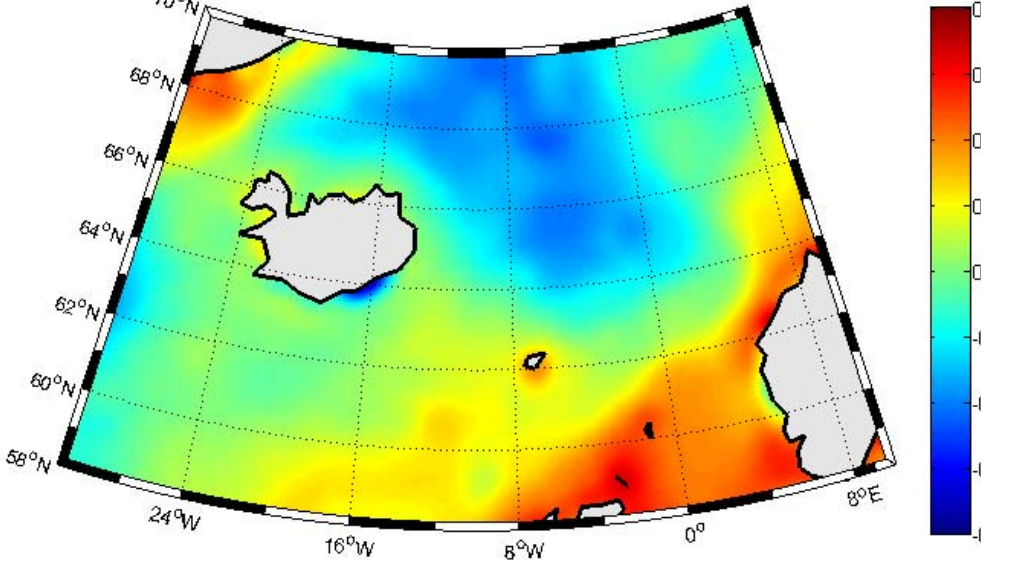

GOCINA project MDT

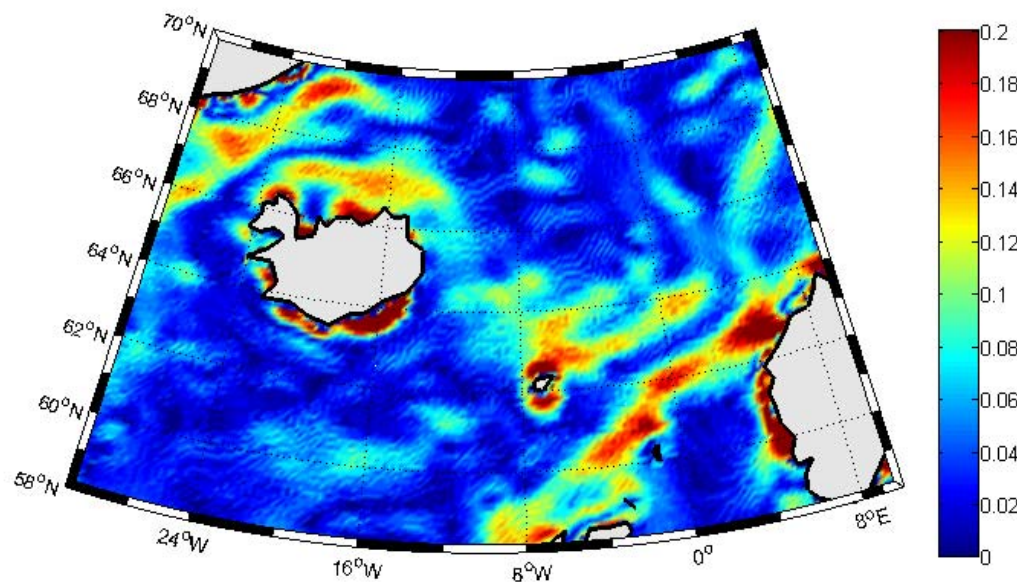

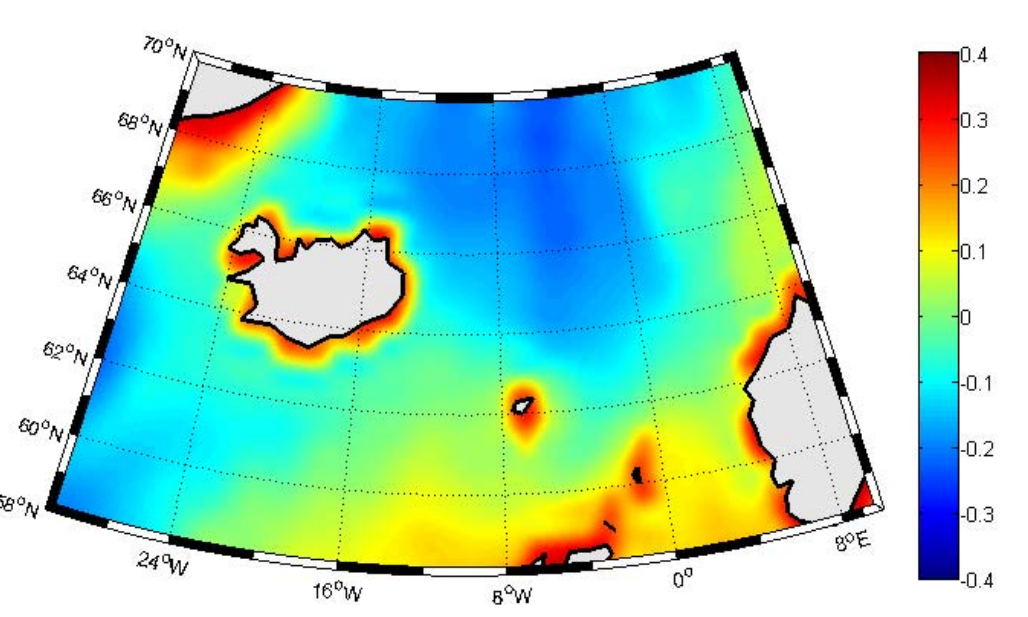

Maximenko MDT
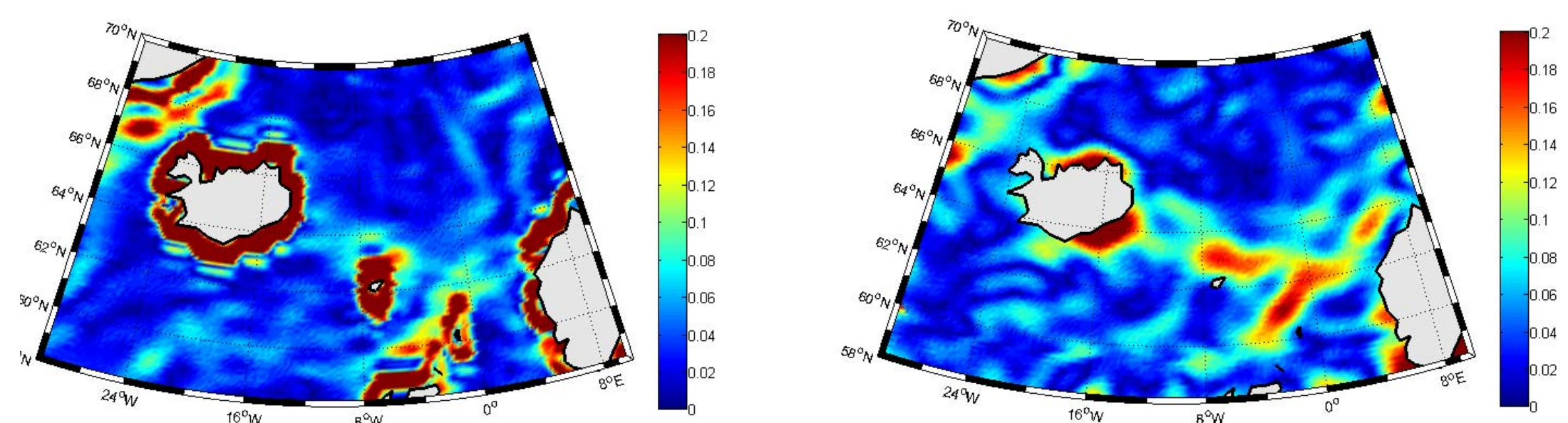

Even though GOCE data provides a better estimation of the MDT in the GOCINA region than any previously obtained using only satellite observations, it could not be concluded whether the regionally enhanced geoid model estimated using GOCE gradients contribute to a further improvement of the determination of the MDT in the GOCINA area.

GOCE Direct MDT current speeds reveal that all of the gross features of the general circulation are clear. However, the MDT calculated in the GOCINA project shows the smallest scale details, which makes it the best ocean circulation representation in this region.

\section{Future work:}

Use RPM method to supplement the tools for investigation on how uncertainties in the conversion from P-wave velocity to density propagate into the gravity model and the density model of the

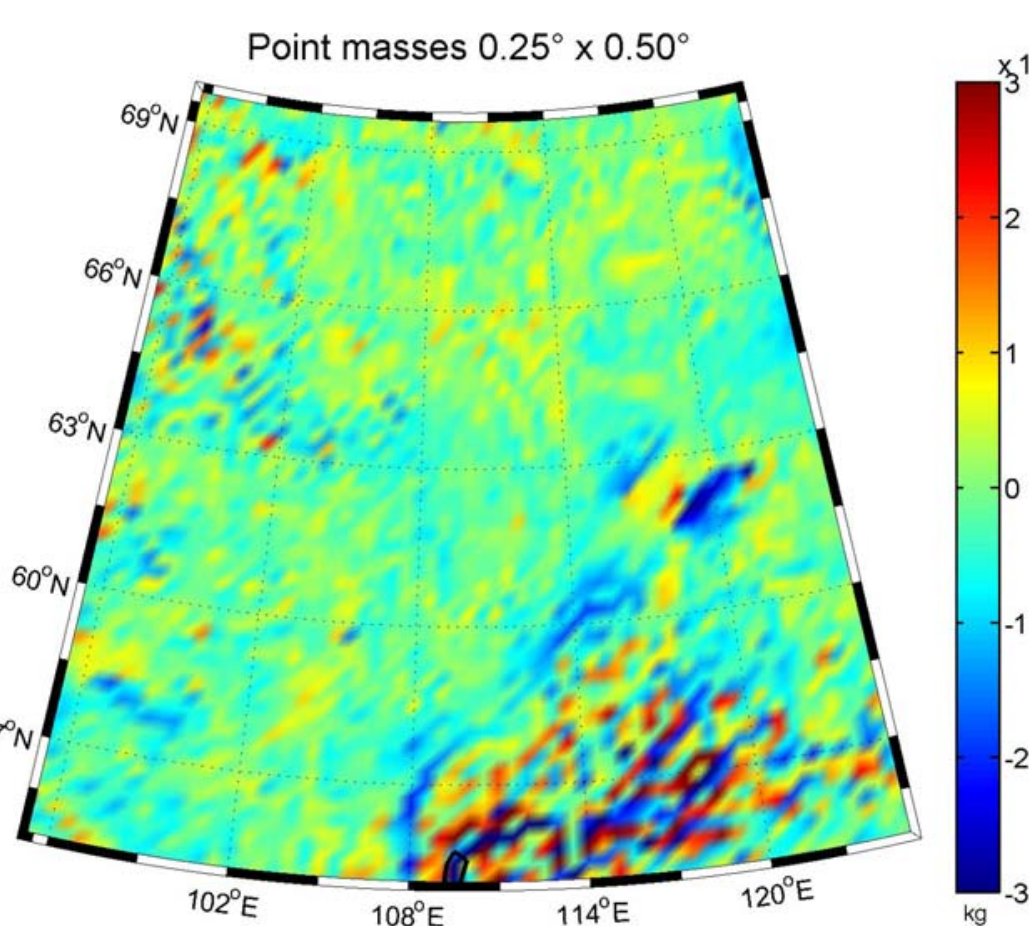
upper mantle.

\section{References}

O. B. Andersen: The DTU10 Global Gravity field and Mean Sea Surface 2011

P. Knudsen: GOCINA: Geoid and Ocean Circulation in the North Atlantic. Technical report, 2005.

N. Maximenko, P. Niiler, M. H. Rio, O. Melnichenko, L. Centurioni, D. Chambers, V. Zlotnicki, and B. Galperin: Mean dynamic topography of the ocean derived from satellite and drifting buoy data using three different techniques. $J$. Atmos. Oceanic Tech., 26(9):1910-1919, 2009.

M. Herceg: GOCE data for Ocean Modelling, PhD thesis, 2012 